\title{
Murine Embryonic Stem Cells Without pig-a Gene Activity Are Competent for Hematopoiesis with the PNH Phenotype but Not for Clonal Expansion
}

\author{
Vittorio Rosti, Gabi Tremml, Vera Soares, Pier Paolo Pandolfi, Lucio Luzzatto, and Monica Bessler \\ Department of Human Genetics, Memorial Sloan-Kettering Cancer Center, Molecular Biology and Cell Biology Programs, Sloan \\ Kettering Institute, 1275 York Avenue, New York, New York 10021
}

\begin{abstract}
Paroxysmal nocturnal hemoglobinuria (PNH) develops in patients who have had a somatic mutation in the $\mathrm{X}$-linked $P I G-A$ gene in a hematopoietic stem cell; as a result, a proportion of blood cells are deficient in all glycosyl phosphatidylinositol (GPI)-anchored proteins. Although the PIG-A mutation explains the phenotype of PNH cells, the mechanism enabling the PNH stem cell to expand is not clear. To examine this growth behavior, and to investigate the role of GPI-linked proteins in hematopoietic differentiation, we have inactivated the pig-a gene by homologous recombination in mouse embryonic stem (ES) cells. In mouse chimeras, pig-a- ES cells were able to contribute to hematopoiesis and to differentiate into mature red cells, granulocytes, and lymphocytes with the PNH phenotype. The proportion of PNH red cells was substantial in the fetus, but decreased rapidly after birth. Likewise, PNH granulocytes could only be demonstrated in the young mouse. In contrast, the percentage of lymphocytes deficient in GPI-linked proteins was more stable. In vitro, pig-a- ES cells were able to form pig-a- embryoid bodies and to undergo hematopoietic (erythroid and myeloid) differentiation. The number and the percentage of pig-a- embryoid bodies with hematopoietic differentiation, however, were significantly lower when compared with wild-type embryoid bodies. Our findings demonstrate that murine ES cells with a nonfunctional pig-a gene are competent for hematopoiesis, and give rise to blood cells with the PNH phenotype. pig-a inactivation on its own, however, does not confer a proliferative advantage to the hematopoietic stem cell. This provides direct evidence for the notion that some additional factor(s) are needed for the expansion of the mutant clone in patients with PNH. $(J$. Clin. Invest. 1997. 100:1028-1036.) Key words: embryoid bodies $\cdot$ ES cells $\bullet$ knockout $\bullet$ GPI $\bullet$ hemoglobinuria
\end{abstract}

Preliminary data on this work has been presented at the International Society for Experimental Hematology meeting, New York, NY, August 23-27, 1996; and at the American Society of Hematology meeting, Orlando, FL, December 6-10, 1996. The present address of Monica Bessler is Division of Hematology-Oncology, Washington University School of Medicine at Washington University Medical Center, 660 S. Euclid Ave., Campus Box 8125, St. Louis, MO 63110-1093.

Address correspondence to Lucio Luzzatto, Department of Human Genetics, Memorial Sloan Kettering Cancer Center, 1275 York Avenue, New York, NY 10021. Phone: 212-639-6165; FAX: 212-7173374; E-mail: 1-luzzatto@ski.mskcc.org

Received for publication 7 April 1997 and accepted in revised form 19 May 1997.

J. Clin. Invest.

(C) The American Society for Clinical Investigation, Inc. 0021-9738/97/09/1028/09 \$2.00

Volume 100, Number 5, September 1997, 1028-1036

http://www.jci.org

\section{Introduction}

Paroxysmal nocturnal hemoglobinuria $(\mathrm{PNH})^{1}$ is an acquired hemolytic anemia characterized by chronic intravascular hemolysis, cytopenia due to bone marrow failure, and a tendency to thrombosis (1). Patients with PNH have a somatic mutation in the X-linked gene PIG-A (glycosyl phosphatidylinositol complementation group A) $(2,3)$, which encodes a protein required for the biosynthesis of glycosyl phosphatidylinositol (GPI) molecules, that serve as membrane anchors for many different cell surface proteins $(4,5)$. Specifically, this protein is required for the transfer of $\mathrm{N}$-acetyl-glucosamine to phosphatidylinositol to form $N$-acetyl glucosaminyl phosphatidylinositol (6). Stretches of sequence homology to a bacterial $\mathrm{N}$-acetyl glucosaminyl transferase suggest that PIG-A is part of the $\alpha-1,6, N$-acetyl glucosaminyl phosphatidylinositol transferase enzyme complex $(7,8)$. In all patients analyzed, the mutation leads to a partial or total deficiency of the PIG-A protein with consequent impaired synthesis of GPI anchors $(5,9$, 10). This mutation must have occurred in an early hematopoietic stem cell, because multiple blood cell lineages are involved. This explains why in patients with $\mathrm{PNH}$, a proportion of blood cells is deficient in all proteins that are GPI-anchored (PNH phenotype). In virtually all patients, blood cells with the $\mathrm{PNH}$ phenotype coexist with phenotypically normal blood cells. The severity of the clinical picture correlates broadly with the size of the PNH clone and with the degree of deficiency in GPIlinked proteins; specifically, the intensity of the hemolysis reflects the number of red cells deficient in CD59 and CD55, and the degree of deficiency in these two proteins (11).

On the other hand, the PIG-A mutation does not explain the growth behavior of the PNH clone. Indeed, it is rather surprising that, despite its inability to express GPI-linked proteins, the PNH hematopoietic stem cell expands and produces a prominent distinct population of blood cells that may contribute substantially to the patient's hematopoiesis. The clone can contribute to all blood cell lineages, indicating that cells belonging to the PNH clone are able to differentiate into mature red cells, granulocytes, monocytes, lymphocytes, and platelets (12).

Early clinical observations that PNH may evolve from or to aplastic anemia, and that bone marrow failure is commonly associated with PNH $(13,14)$, led to the hypothesis that the absence of GPI-linked proteins paradoxically provides the $\mathrm{PNH}$ clone with a growth or a survival advantage in a background

1. Abbreviations used in this paper: $2 \beta-\mathrm{ME}, 2 \beta$-mercaptoethanol; d.p.c., days postcoitum; EB, embryoid body; ES cells, embryonic stem cells; FACS, flow cytometric analysis; GPI, glycosyl phosphatidylinositol; IMDM, Iscove modified Dulbecco's medium; IRES, internal ribosomal reentry site; Pig-A, glycosyl phosphatidylinositol complementation group $\mathrm{A}$; $\mathrm{PNH}$, paroxysmal nocturnal hemoglobinuria; rhEpo, recombinant human erythropoietin; rmSCF, recombinant murine stem cell factor. 
that impairs normal hematopoiesis $(15,16)$. This hypothesis was further supported by the more recent finding that in many patients, more than one PNH clone coexist (17).

To further investigate this hypothesis by a direct study of hematopoietic stem cell growth and differentiation in the absence of a functional pig-a gene, we have inactivated the pig-a gene in mouse embryonic stem cells (ES cells), and then analyzed hematopoiesis in chimeric mice in vivo and in embryoid bodies (EBs) in vitro. We found that pig- $a-$ ES cells can undergo full hematopoietic differentiation and mature into red cells, granulocytes, and lymphocytes. Neither in vivo nor in vitro inactivation of the pig- $a$ gene, however, provides the hematopoietic stem cell with a growth advantage. These findings demonstrate for the first time cell-autonomous hematopoiesis by pig- $a-$ cells; they also show that a pig- $a$ mutation alone is not enough to cause $\mathrm{PNH}$, thus providing further support to the notion that an additional environmental factor is required.

\section{Methods}

ES cell line culture. The 129 Sv-derived CJ7 ES cell line (18) was maintained in an undifferentiated state by culturing on a monolayer of mytomycin-treated primary embryonic fibroblasts in the presence of $1,000 \mathrm{U} / \mathrm{ml}$ of leukemia inhibitory factor (GIBCO, BRL, Gaithersburg, MD) as described (19). Subconfluent plates were passed every $2-3 \mathrm{~d}$ by gentle trypsinization with $0.125 \%$ Trypsin/0.01\% EDTA (GIBCO BRL) for $5 \mathrm{~min}$ at $37^{\circ} \mathrm{C}$.

Targeted disruption of the pig-a gene in ES cells. PCR primers specific for the human exon 2 (upstream primer: 5' GTACATATTTGTTCGGGA 3'; reverse primer: 5' CTTTCTGTAAACAAGTCTG $3^{\prime}$ ) were used to amplify the homologous 400-bp fragment from mouse genomic DNA. The amplified fragment was used to screen a mouse $129 \mathrm{~Sv}$ genomic library (129SVJ; Stratagene Inc., La Jolla, CA) at high stringency (20). Out of $10^{6}$ recombinant phages, eight overlapping phages were isolated. The isolated $25-\mathrm{kb}$ genomic region covered the entire pig- $a$ gene (21). Restriction sites relevant for the cloning procedure were determined (see Fig. 1).

Two different targeting vectors were constructed (vector 1 and vector 2) (Fig. 1): for vector 1, a 10.5-kb NotI-XhoI fragment of genomic DNA encompassing exon 2-5 and $2.4 \mathrm{~kb}$ of intron 2 was subcloned into the Bluescript vector SK (Stratagene Inc.). The 1.92-kb NcoI-EcoRI fragment encompassing $320 \mathrm{bp}$ of the $3^{\prime}$ end of pig- $a$ exon 2 and $1.6 \mathrm{~kb}$ of intron 2 was replaced with the XhoI-BamHI insert from the pMC1neoPolyA (Stratagene Inc.) vector by the use of BclI linkers at the NcoI site. A three-piece ligation joined the 4.1-kb NotI-XhoI fragment containing neoPolyA, the 4.3-kb EcoRI (changed to XhoI by the use of linkers)-XbaI fragment, containing the rest of intron 2 and exons 3, 4, and 5, with the $5.6 \mathrm{~kb}$ of PyTK vector cut with XbaI-NotI, which contains the herpes simplex virus thymidine kinase gene under the control of a mutated polyoma enhancer (see Fig. 1).

Vector 2 is similar to vector 1, but contains instead of the neoPolyA, a NEO-IRES-LacF cassette (see Fig. 1). The NEO-IRES-LacF cassette contains the neo gene under the control of the thymidine kinase promoter of pMC1neo (Stratagene Inc.). The BamHI-NcoI fragment of the internal ribosomal reentry site (IRES) from encephalomyocarditis virus (provided by M. Sadelain, Memorial Sloan Kettering Cancer Center, NY), and the NcoI-BglII fragment of pnLacF-puc18 (obtained from A. Kottmann, Columbia University, NY) encoding the bacterial $\beta$-galactosidase with a nuclear localization signal derived from SV40 were inserted into the BamHI site of pMC1neo. The NEO-IRES-LacF cassette was linked to the NcoI site of pig- $a$ exon 2 by the use of BclI linkers. The following cloning steps were identical to the cloning steps described for vector 1 .

To introduce the targeting vectors into the endogenous gene, 40 $\mu \mathrm{g}$ of vector 1 or 2 were linearized at the SalI or NotI site, respectively, and electroporated into $2 \times 10^{7} \mathrm{CJ} 7 \mathrm{ES}$ cells in a volume of 0.9 $\mathrm{ml}$ at $240 \mathrm{~V}$ and $560 \mu \mathrm{FD}$ by the use of a Bio-Rad Gene pulser (BioRad Laboratories, Richmond, CA). After $24 \mathrm{~h}$ of culture, the medium was supplemented with $400 \mu \mathrm{g} / \mathrm{ml}$ G418 (Geneticin; Sigma Chemical Co., St. Louis, MO) and $2 \mu \mathrm{M}$ Gancyclovir $\left(\right.$ Cytovene $^{\circledR}$; Syntex Inc., Palo Alto, CA). Double selection was carried out for $6 \mathrm{~d}$. 400 ES cell clones from each electroporation were isolated. Individual clones were expanded, and genomic DNA was prepared as described (22). Homologous recombination in the pig- $a$ locus in doubleresistant ES cell clones was assessed by Southern blot analysis (20). Two probes outside the region of homology ( $5^{\prime}$ and $3^{\prime}$ probe) and one internal probe (neo probe) were used to assess homologous recombination (see Fig. 1).

Generation of pig-a negative chimeric mice. Seven different homologous recombined ES cell clones, showing normal $40 \mathrm{XY}$ karyotype (23) (clone 86, 91, 97, 108, 185, and 2A8), were used for the production of chimeric mice. 5-10 pig-a- ES cells were injected into C57BL/6J blastocysts obtained from females $3.5 \mathrm{~d}$ postcoitum (d.p.c.). After injection, blastocysts were transferred into pseudopregnant $(\mathrm{CBA} \times \mathrm{C} 57 \mathrm{BL} / 6 \mathrm{~J}) \mathrm{f} 1$ mice. Coat chimerism $(\%$ of agouti coat color $)$ was estimated at the age of $2 \mathrm{wk}$. All animal procedures were in compliance with the NIH Guide for the Care and Use of Laboratory Animals.

Flow cytometric analysis (FACS). Contribution of pig-a- ES cells to hematopoiesis in chimeric mice was assessed by FACS analysis of peripheral blood using FITC-conjugated antibodies towards GPI-linked surface antigens: CD24 (heat stable antigen) for red blood cells, Gr-1 for granulocytes, and CD48 for lymphocytes. Lineage specificity was determined using phycoerythrin-conjugated anti-
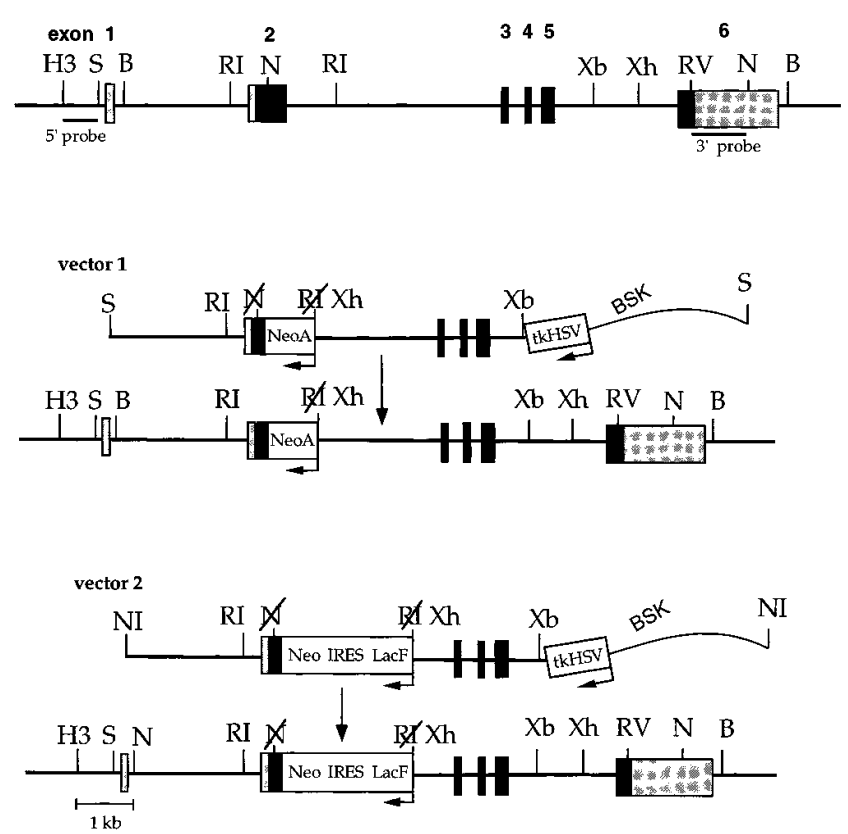

Figure 1. Targeted disruption of the pig- $a$ gene. A partial restriction map of the pig- $a$ gene is shown (top). Underneath are displayed the two replacement vectors (vector 1 and vector 2 ) in linear forms. The predicted structure of the targeted allele for each vector is shown beneath the respective targeting construct. pig- $a$ exons are indicated by boxes. Black boxes represent coding, and gray boxes noncoding sequences. Genomic fragments (5' and 3' probe) were used to assess homologous recombination of Southern blots. The thymidine kinase (HSVtk) and the neomycin (NeoA) gene or NEO-IRES-LacF cassettes (empty boxes) were inserted in reverse orientation with respect to the pig- $a$ gene. H3, HindIII; RI, EcoRI; B, BamHI; Xh, XhoI; Xb, XbaI; N, NcoI; S, SalI; NI, NotI; RV, EcoRV; BSK, Bluescript vector $\mathrm{KS} \mathrm{II}+$. 
CD22 and anti-B220 antibodies for B-lymphocytes, anti-TCR $\alpha \beta$ and anti-CD3 for T lymphocytes, and anti-CD11b for granulocytes. FITCor PE-labeled isotypic control antibodies were used as a control. All the antibodies were purchased from PharMingen, San Diego, CA. 1-2 $\mu \mathrm{l}$ of blood was used for the immunostaining of red cells, $25 \mu \mathrm{l}$ for the staining of white cells. For the analysis of fetal blood, the fetuses were obtained by cesarean section; after careful washing in PBS, blood was obtained from the umbilical cord and from cervical vessels.

Blood cell count. Blood samples were obtained by puncture of the retroorbital plexus of anesthetized mice using heparinized capillary tubes. Red blood cell count, white blood cell count, hemoglobin, mean red cell volume, hematocrit, and platelet count were determined by the use of an automated blood cell counter.

Fetal liver hematopoietic progenitor assay. Single-cell suspensions from livers from day 14 chimeric fetuses were obtained as previously described (24). $2 \times 10^{4}$ fetal liver cells were plated in 30-mm Petri dishes in a 1-ml aliquot of Iscove modified Dulbecco's medium (IMDM; GIBCO BRL) supplemented with $30 \%$ FBS (HyClone, Lo-

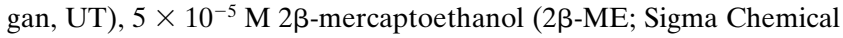
Co.), 3 IU recombinant human erythropoietin (rhEpo, Procrit; Ortho Diagnostic Systems, Inc., Raritan, NJ), 20 ng recombinant murine stem cell factor (rmSCF; Genzyme Corp., Cambridge, MA), 20 ng recombinant murine interleukin 3 (Genzyme Corp.) and $0.9 \%$ (wt/vol) methylcellulose (Stem Cell Technologies Inc., Vancouver, BC). Each assay was performed in duplicate. After incubation of $7 \mathrm{~d}$ at $37^{\circ} \mathrm{C}, 5 \%$ $\mathrm{CO}_{2}$, the number of hematopoietic colonies was scored under an inverted microscope.

In vitro differentiation of ES cells; primary culture for the embryoid body formation and hematopoietic differentiation. EB formation was obtained using the methylcellulose assay described by Wiles and Keller (25) with minor modifications. Single-cell suspension was obtained from subconfluent and undifferentiated ES cells using $0.25 \%$ Trypsin with $1 \mathrm{mM} \mathrm{Na}{ }_{2}$ EDTA (GIBCO BRL); feeder cells were removed by trituration through a fine-bore Pasteur pipette followed by adherence to plastic for $1 \mathrm{~h}$ at $37^{\circ} \mathrm{C}$. ES cells were then plated in a 1-ml aliquot of IMDM (GIBCO BRL) supplemented with $15 \%$ FBS (HyClone), $450 \mu \mathrm{M}$ monothioglycerol (Sigma Chemical Co.), 3 IU recombinant human rhEpo (Ortho Diagnostic Systems Inc., Raritan, $\mathrm{NJ}$ ) and $0.9 \%(\mathrm{wt} / \mathrm{vol})$ methylcellulose (Stem Cell Technologies Inc.). Wild-type CJ7 ES cells were plated at a density of $5 \times 10^{3}$ cells $/ \mathrm{ml}$; pig- $a-$ ES cells were plated at $1.5 \times 10^{4}$ cells $/ \mathrm{ml}$. For the plating of small aggregates ES cells were first grown for $24 \mathrm{~h}$ in bacterial Petri dishes in IMDM (GIBCO BRL), supplemented with 15\% FBS (HyClone) and $450 \mu$ M MTG (Sigma Chemical Co.) in liquid culture, and then carefully plated in methylcellulose supplemented as above. Methylcellulose assays were performed in duplicate. After 7-10 d incubation at $37^{\circ} \mathrm{C}$ in a fully humidified atmosphere supplemented with $5 \% \mathrm{CO}_{2}$, the number of EBs formed was scored using an inverted microscope. Hematopoietic differentiation within the EBs was assessed according to the presence of hemoglobinized cells and/or the appearance of evading macrophages. The identity of these cells was confirmed by light microscopy of May Grünwald Giemsa or Wrightstained cytospin preparations obtained from individual EBs.

Secondary cultures for enumeration of hematopoietic progenitor cells. EBs developing in the primary culture were individually picked after $6 \mathrm{~d}$ incubation at a time when hematopoietic differentiation becomes apparent. Only EBs with signs of hematopoietic differentiation were picked; a single-cell suspension was obtained by incubation in $0.125 \%$ trypsin for $5 \mathrm{~min}$ at $37^{\circ} \mathrm{C}$ followed by mechanical disaggregation. Cells were then plated in a 1-ml aliquot of IMDM (GIBCO BRL) supplemented with $30 \%$ FBS (HyClone), $5 \times 10^{-5} \mathrm{M} 2 \beta$-ME (Sigma Chemical Co.), 3 IU rhEpo (Ortho Diagnostic Systems, Inc.), $20 \mathrm{ng}$ rmSCF (Genzyme Corp.), 20 ng rm IL-3 (Genzyme Corp.), 50 ng recombinant human granulocyte colony stimulating factor (Genzyme Corp.) and $0.9 \%$ (wt/vol) methylcellulose (Stem Cell Technologies Inc.). Hematopoietic colonies were identified according to standard criteria (26).

DNA extraction and PCR analysis. Individually isolated EBs or fetal liver CFU-GM were placed in $9 \mu 150 \mathrm{mM} \mathrm{NaOH}$ and boiled for $5 \mathrm{~min} ; 1 \mathrm{M}$ Tris- $\mathrm{HCl}, \mathrm{pH}$ 8, and water were then added to a final volume of $15 \mu \mathrm{l}$. PCR analysis was performed using the following primers: 5' TTTGCCTCTGAGAGTCATGT 3' (273, upstream primer for both wild-type and pig- $a-$ ES cells); 5' AAAGCCACCATACAGAATGA 3' ( $\mathrm{I}_{2}$, reverse primer for wild-type ES cells); 5' AGCGCCGGTCGCTACCATTACC 3' (lacF2, reverse primer for pig- $a-\mathrm{ES}$ cells; vector 2) and 5' CCGCTTCCTCGTGCTTTAC 3' (3'Neo, reverse primer for pig- $a-$ ES cells; vector 1$)$.

\section{Results}

Targeted disruption of pig-a in ES cells. The pig-a gene was disrupted in CJ7 ES cells by the replacement of 320-bp of the $3^{\prime}$ end of exon 2 and $1.6 \mathrm{~kb}$ of intron 2 by the neoPolyA or the NEO-IRES-LacF cassette, respectively. This approach was chosen because previous analysis of the $P I G-A$ gene from patients with PNH showed that the $3^{\prime}$ end of exon 2 is essential for PIG- $A$ activity (3). Murine pig- $a$ maps to the X-chromosome (X-F3/4) (21), and the CJ7 ES cell line is of male origin. Recombinant ES cell clones are therefore expected to have no pig- $a$ activity. Seven homologously recombined ES cell clones were obtained using replacement vector 1 , and one homologously recombined ES cell clone using vector 2 . The absence of CD24 surface antigen by FACS analysis confirmed inactivation of the pig- $a$ gene in these clones (data not shown). There was no obvious difference between pig- $a-$ and wild-type ES cells in their growth pattern, or in their adhesion to primary embryonic fibroblasts.

Generation of chimeric mice. Six individual ES cell clones $(86,91,95,97,108$, and 2A8) shown to be euploid by karyotype analysis were injected into C57BL/6J blastocysts for the generation of chimeric mice. The number of pig- $a-$ ES cells injected was critical since the injection of more than 10 cells failed to produce any viable chimeras. Twenty transfers of 10 12 blastocysts gave rise to 54 newborns (Table I). The low number of pregnancies, the small litter sizes, and the high perinatal lethality suggest that a high contribution of pig- $a-$ cells to the embryo is not compatible with life.

Seven mice (three males and four females) had blood cells deficient in GPI-linked proteins, ranging from $1-5 \%$. One of these mice was completely black (mouse 86.3), whereas the remaining six mice had a low percentage of agouti coat color (estimated 5\%). During the observation period of 13 mo three of the seven mice with contribution of pig- $a-$ red cells died; mouse 95.93 died of unknown cause at 4 wk of age; mouse

Table I. Generation of pig-a-Chimeric Mice

\begin{tabular}{|c|c|c|c|c|c|c|}
\hline $\begin{array}{l}\text { ES cell } \\
\text { clone }\end{array}$ & $\begin{array}{c}\text { No. of } \\
\text { pregnancies }\end{array}$ & $\begin{array}{c}\text { No. of } \\
\text { newborns/ } \\
\text { alive }\end{array}$ & $\begin{array}{c}\text { No. of } \\
\text { coat } \\
\text { chimeras }\end{array}$ & $\begin{array}{l}\text { No. of } \\
\text { chimeras with } \\
\text { CD24- } \\
\text { red cells }\end{array}$ & $\begin{array}{c}\text { No. of } \\
\text { chimeras } \\
\text { with Gr1- } \\
\text { granulocytes }\end{array}$ & $\begin{array}{c}\text { No. of } \\
\text { chimeras } \\
\text { with CD48- } \\
\text { lymphocytes }\end{array}$ \\
\hline 86 & 2 & $8 / 7$ & 0 & 1 & 0 & 0 \\
\hline 91 & 1 & $5 / 5$ & 1 & 1 & 0 & 0 \\
\hline 95 & 3 & $17 / 16$ & 4 & 4 & 0 & 0 \\
\hline 97 & 2 & $5 / 3$ & 0 & 0 & 0 & 0 \\
\hline 108 & 2 & $7 / 0$ & 0 & 0 & 0 & 0 \\
\hline $2 \mathrm{~A} 8$ & 4 & $12 / 6$ & 1 & 1 & 1 & 1 \\
\hline Total & 14 & $54 / 37$ & 6 & 7 & 1 & 1 \\
\hline
\end{tabular}


C57BL/6

A

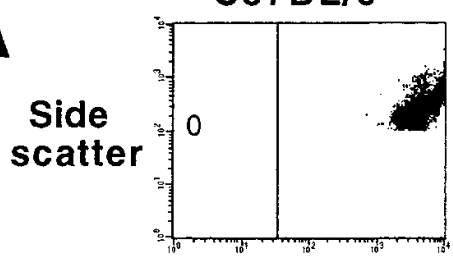

CD24-FITC

B

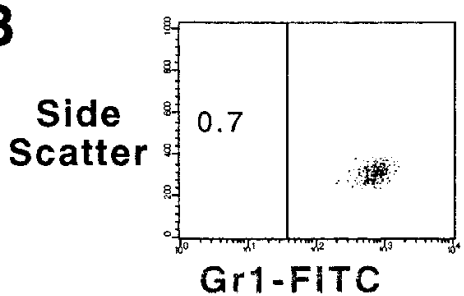

$\mathbf{C}$
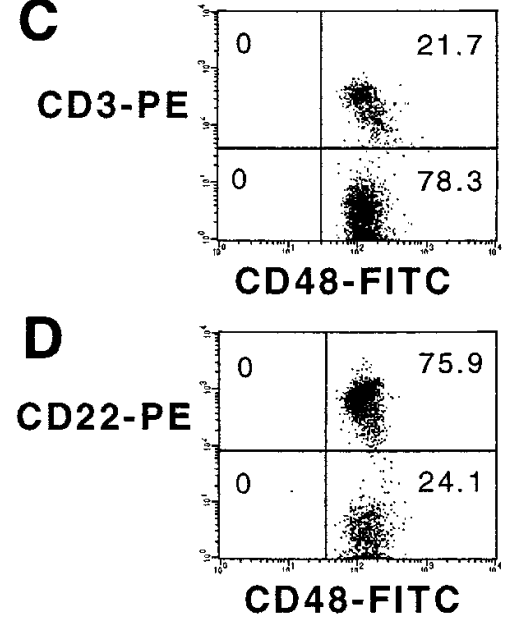

Chimera $2 A 8$
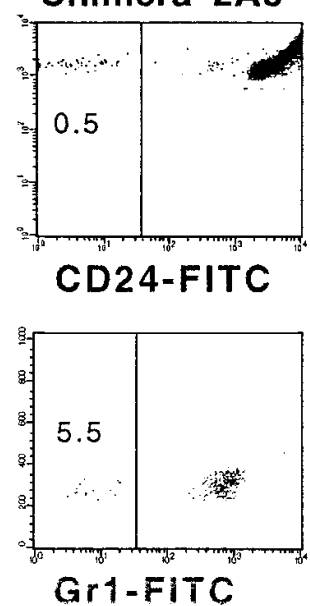

GrI-FITC
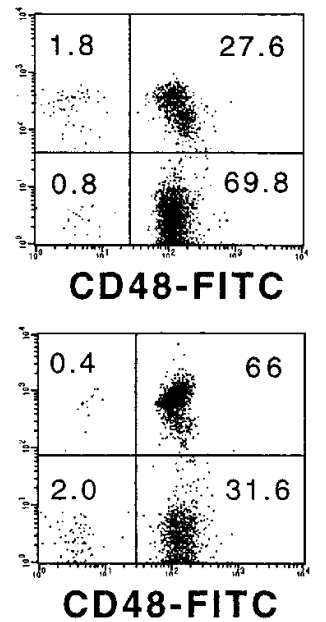

Figure 2. Flow cytometric analysis of peripheral blood cells of chimera $2 \mathrm{~A} 8$ at the age of $4 \mathrm{wk}$. Peripheral blood cells of a C57BL/6J control mouse and chimera $2 \mathrm{~A} 8$ were stained with monoclonal antibodies towards GPI-linked proteins: CD24 on red cells, Gr1 on granulocytes, and CD48 on lymphocytes. $A$ shows the dot analysis of red cells, $B$, the dot analysis of granulocytes, $C$, the dot analysis of T-lymphocytes, and $D$, the dot analysis of B-lymphocytes. Red cells and granulocytes were identified by their light scatter characteristics; $\mathrm{T}-$ and $\mathrm{B}$ - lymphocytes were identified by lineage-specific antibodies towards CD3 and CD22, respectively. Numbers in the quadrants indicate the percentage among total cells.

95.1011 died of a bowel obstruction at 4 wk of age; mouse 91.5 died at $28 \mathrm{wk}$ of age after he suffered from an ulcerative skin disease (see below).

Chimeric males were fertile, but despite several breeding attempts, they failed to produce viable offsprings heterozygous for the nonfunctional pig-a gene; i.e., germline transmission was not obtained.

pig-a negative blood cells in adult chimeric mice. Of the seven mice with a distinct population of red cells deficient in CD24, one (mouse 2A8) had also a small population of granulocytes deficient in the Gr-1 antigen, as well as a population of lymphocytes (both B and T cells) deficient in CD48 (Fig. 2). With the exception of one mouse (see below), peripheral blood counts of mice with pig- $a$ - blood cells, obtained at the ages of 1,2, 7, and 12 mo, were not significantly different from peripheral blood counts of age-matched C57BL/6J controls (Table II).

In seven chimeric mice that were followed up regularly for $56 \mathrm{wk}$, the percentage of GPI-negative red cells decreased rapidly (Fig. 3), and by the age of 3 mo they were hardly detectable, except in one mouse (2A8) in which they persisted over an observation period of 13 mo (Fig. 3). This same mouse was the only one in which Gr-1 negative granulocytes were detected in the initial analysis performed at the age of $4 \mathrm{wk}$. Repeated analysis at the ages of 3,6, and 9 mo failed to show Gr-1 negative granulocytes.

In mouse $2 \mathrm{~A} 8$ at the age of $4 \mathrm{wk}$, we also found that $2.6 \%$ of lymphocytes were deficient in GPI-linked proteins. More specifically, two-color FACS analysis revealed that $6.1 \%$ of T-lymphocytes and $0.6 \%$ of B-lymphocytes were negative for CD 48. At the age of 9 mo, 3.6\% of T-lymphocytes and $1.7 \%$ of B-lymphocytes were still negative for CD48.

Mouse 91.5 at the age of 7 mo developed pancytopenia (see Table II), and at the same time showed an increase in the proportion of CD24-negative red cells from 0.2 to $1.7 \%$ (see Fig. 3 ). This mouse had also developed from the age of 6 mo a skin lesion on the dorsum of the neck between the scapulae. The lesion was intensely pruritic and rapidly worsened. The skin changes resembled the chronic idiopathic ulcerative dermatitis reported to occur in $\mathrm{C} 57 \mathrm{BL} / 6$ mice and related strains $(27,28)$. As the dermatitis worsened, the mouse became cachectic, and its performance status deteriorated. The mouse died shortly after the last blood analysis. The pathogenesis of this condition is unknown, but it has been reported to respond to corticosteroids (28), as though it might be autoimmune-mediated.

Table II. Hemoglobin Level, White Blood Cell and Platelet Count of Wild-type and pig-a-Chimeric Mice

\begin{tabular}{|c|c|c|c|c|c|c|c|c|c|}
\hline \multirow[b]{2}{*}{ Age } & \multicolumn{3}{|c|}{ C57BL/6* } & \multicolumn{3}{|c|}{ pig-a- chimeras $^{\ddagger}$} & \multicolumn{3}{|c|}{91.5 chimera $^{8}$} \\
\hline & $\mathrm{Hb}$ & WBC & Plt & $\mathrm{Hb}$ & WBC & Plt & $\mathrm{Hb}$ & WBC & Plt \\
\hline mo & $g / d l$ & $10^{3} / \mu l$ & $10^{3} / \mu l$ & $g / d l$ & $10^{3} / \mu l$ & $10^{3} / \mu l$ & $g / d l$ & $10^{3} / \mu l$ & $10^{3} / \mu l$ \\
\hline 1 & $13.9 \pm 1.0$ & $4.1 \pm 1.0$ & $1190 \pm 232$ & $12 \pm 2.8$ & $3.2 \pm 0.9$ & $1502 \pm 575$ & 12.5 & 4.4 & 1650 \\
\hline 2 & $15.3 \pm 0.6$ & $4.4 \pm 1.4$ & $1266 \pm 90$ & $15.1 \pm 0.4$ & $4.2 \pm 1.5$ & $1268 \pm 49$ & 16 & 4.2 & 1245 \\
\hline 7 & $12.6 \pm 1.7$ & $4.3 \pm 1.4$ & $1246 \pm 95$ & $14.6 \pm 3.3$ & $6.4 \pm 3.1$ & $1073 \pm 143$ & 6.5 & 1.8 & 640 \\
\hline 12 & $13.8 \pm 0.8$ & $7.9 \pm 1.3$ & $1321 \pm 244$ & $14.4 \pm 1$ & $10.1 \pm 1.6$ & $1280 \pm 218$ & NA & NA & NA \\
\hline
\end{tabular}

$\mathrm{Hb}$, hemoglobin; WBC, white blood cell; plt, platelet; NA, not applicable. *Each value represents the mean \pm SD obtained from three mice at the indicated age. ${ }^{*}$ Each value represents the mean \pm SD obtained from six mice at 1 mo and from four mice at 2,7 , and 12 mo of age. ${ }^{8} \mathrm{Chimera} 91.5$ died at the age of 7 mo. 


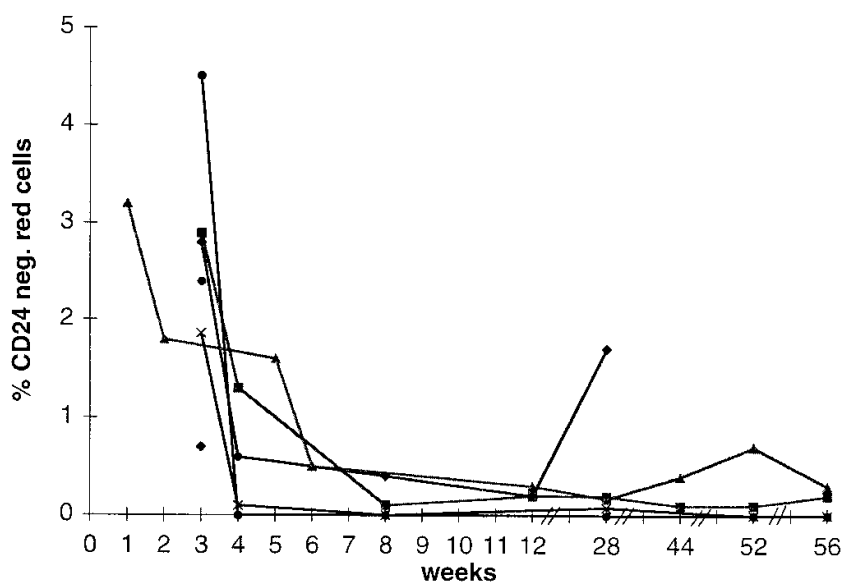

Figure 3. Time course of PNH red cells in pig- $a-$ chimeric mice during the first 13 mo of life. The proportion of CD24-deficient red cells in seven mice with pig- $a$ - red cells was determined by flow cytometry at different time points. During the observation period, three mice died (+). Connected black diamonds, $91.5+$; connected black squares, 86.3; connected black triangles, 2A8; connected cross marks, 95.109; unconnected black circles, 95.1011+; connected black circles, 95.101; unconnected black diamonds, $95.93+$.

pig-a negative blood cells in chimeric fetuses. The rapid fall in pig- $a-$ red cells during the first weeks of life suggested that the contribution of pig- $a-$ ES cells to erythropoiesis might have been higher before birth. Therefore, we analyzed red cells in 43 fetuses between 12 and 19 d.p.c. Eleven fetuses showed pig- $a-$ red cells, and these ranged in percent from 1.8 to 36 with a mean of $12.6 \%$ (Fig. 4).
CFU-GMs grown from the liver of a 14 d.p.c. fetus in which $7 \%$ of red cells were deficient in CD24 confirmed that pig-aES cells can contribute to myelopoiesis. In 5 out of 50 individually picked CFU-GM (10\%), PCR analysis showed that the pig- $a$ gene was recombined; in the remaining 45 the wild-type pig- $a$ allele was amplified (data not shown).

Hematopoietic differentiation in embryoid bodies. EBs were obtained from both wild-type and pig- $a-$ ES cells (clones 97, 108, and 2A8). pig- $a-$ ES cells, however, formed fewer EBs when compared with wild-type ES cells (see Table III). EBs derived from pig- $a-$ ES cells were also smaller $(1.02 \pm 0.1 \times$ $10^{3}$ cells per EB compared to $2.19 \pm 0.2 \times 10^{3}$ cells in control EB) (Table IV). In addition, pig- $a-$ EBs often had an irregular shape, and were less organized in their structure, when compared to the near-spherical bodies obtained from $\mathrm{CJ} 7$ wild-type ES cells (see Fig. 5). EBs derived from two out of three pig- $a-$ ES cell clones (clones 97 and 2A8) were competent for hematopoietic differentiation (Fig. 5 and Table III). Light microscopy evaluation of May Grünwald Giemsa or Wright-stained cytospin preparations confirmed the presence of cells belonging to both the erythroid and the myeloid lineages (Fig. 5). Cytospins showed that in pig- $a-$ EBs the absolute number of hematopoietic cells was lower when compared to the absolute number of hematopoietic cells in wild-type EBs (see Table IV). Differential counts also showed that red cells and macrophages were almost equally represented in pig- $a-$ and wild-type EBs (Table IV) but, in contrast to the wild-type EBs, fewer granulocytes were detected in pig-aEBs (Table IV). The unlikely possibility that pig- $a-$ EBs might have been contaminated by normal cells was ruled out by PCR analysis of DNA from individual EBs with hematopoietic differentiation. This analysis showed amplification of
A

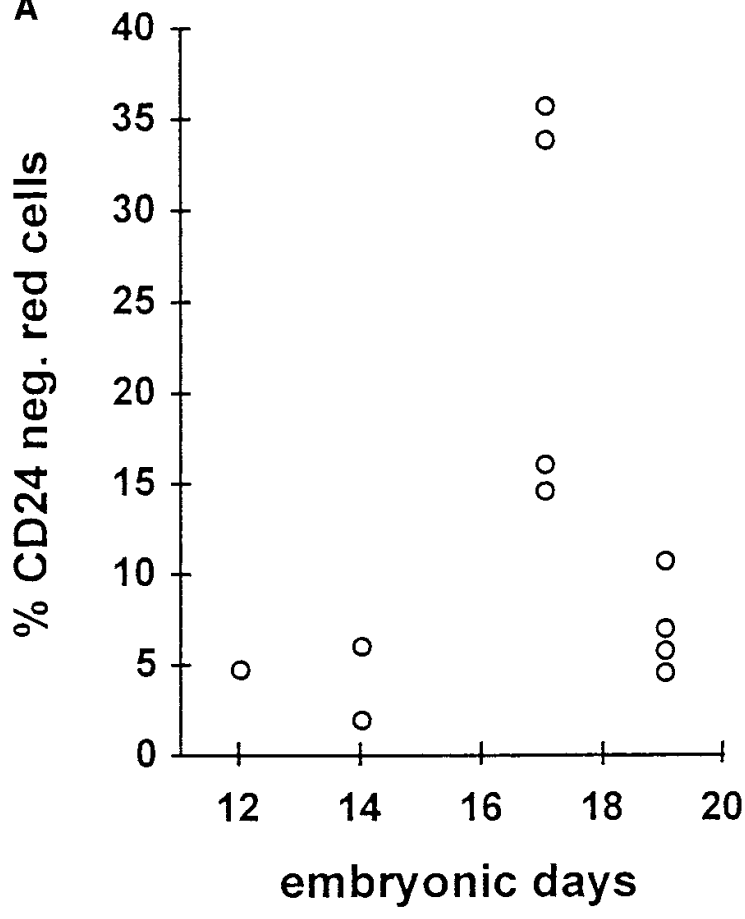

B

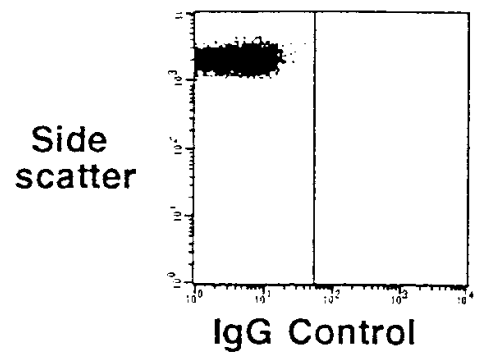

pig-a- chimera 1

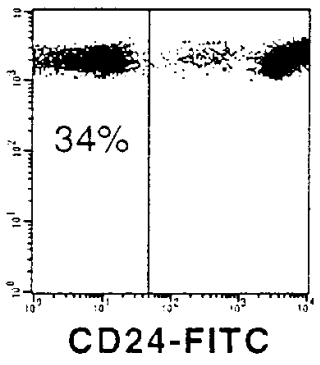

C57BL/6

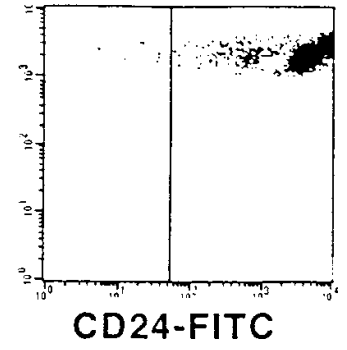

pig-a- chimera 2

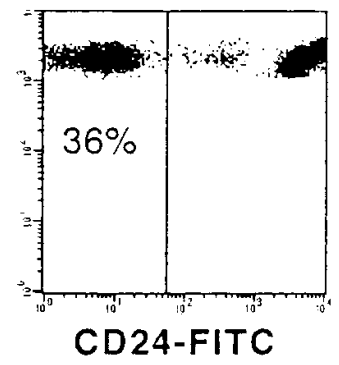

Figure 4. CD24-deficient red cells in pig-a - chimeric fetuses. $A$ shows the proportion of CD24-deficient red cells as determined by flow cytometry in 11 fetuses with pig- $a$ - red cells at age between day 12 (E12) and day 19 (E19) p.c. $B$ shows the dot analysis of red blood cells from the two pig- $a$ - chimeric fetuses with the highest contribution of pig- $a-$ red cells, and a C57BL/6J control fetus at day 17 p.c. 


\begin{tabular}{|c|c|c|c|c|c|}
\hline \multirow[b]{2}{*}{ Plating as } & & pig-a+ & \multicolumn{3}{|c|}{ pig-a- } \\
\hline & ES cell clone & $\mathrm{CJ} 7 *$ & $2 \mathrm{~A} 8$ & 97 & 108 \\
\hline & & $n=4$ & $n=4$ & $n=2$ & $n=1$ \\
\hline \multirow[t]{2}{*}{ Single-cell suspension } & No. of EBs & $846 \pm 273$ & $137 \pm 30$ & $63 \pm 10$ & 61 \\
\hline & No. of EBs with hematopoiesis (\%) & $339 \pm 195(38)$ & $6 \pm 5(4)$ & $6 \pm 2(6)$ & 0 \\
\hline \multirow[t]{2}{*}{ Cell aggregates } & No. of EBs & $1764 \pm 132$ & $152 \pm 33$ & $146 \pm 22$ & 49 \\
\hline & No. of EBs with hematopoiesis (\%) & $504 \pm 144(28)$ & $24 \pm 3(15)$ & $61 \pm 16(41)$ & 0 \\
\hline
\end{tabular}

*EBs no. is normalized to $1.5 \times 10^{4}$ ES cells plated. $n=$ number of experiments performed.

the recombined pig- $a$ gene only, confirming that hematopoietic differentiation occurs in EBs that lack GPI-linked proteins (Fig. 6). No hematopoietic differentiation was obtained in pig- $a$ - ES cell clone 108. EBs obtained from three nonhomologous recombined ES cell clones had similar percentage of hematopoietic differentiation $(25 \pm 3 \%)$ compared to wild-type EBs $(29 \pm 2 \%)$.

Plating of ES cell aggregates instead of single-cell suspension may cause an increase in hematopoietic differentiation in certain cell lines (29). Therefore, we also carried out experiments in which cells, before plating, were kept for $24 \mathrm{~h}$ in liquid culture (during which time the cells formed small aggregates). By this procedure, the number of EBs formed by pig-a- ES cell clones 97 and 2A8 and CJ7 wild-type ES cells was markedly increased. The percentage of hematopoietic differentiation was also increased in the EBs derived from pig- $a-$ ES cell clones 97 and 2A8, whereas it did not change significantly in EBs derived from wild-type CJ7 ES cells (Table III). With pig- $a-$ ES cell clone 108 after plating small aggregates, neither the number of bodies changed nor hematopoietic differentiation was obtained (Table III).

In vitro progenitor colony assay. The above data clearly show that pig- $a$ - ES cells can give origin to mature blood cells, although with reduced yield. To test at which stage of differentiation the pig- $a$ - cells may be impaired, we tested hematopoietic progenitor cells within the EBs by replating disaggregated EBs at various time points in methylcellulose in the presence of Epo, SCF, IL-3, and G-CSF. Wild-type EBs gave the highest yield of secondary colony formation at day 6. pig- $a-\mathrm{EBs}$ were also able to give rise to hematopoietic colonies in the secondary plating assay (Table V), but again with a much lower

Table IV. Hematopoietic Characterization of Wild-type and pig- $a-E B s$

\begin{tabular}{|c|c|c|c|c|c|c|}
\hline & \multirow{2}{*}{$\begin{array}{c}\text { No. of } \\
\text { cells*/EB } \\
\text { plated directly }\end{array}$} & \multirow{2}{*}{$\begin{array}{l}\text { No. of } \\
\text { cells*/EB } \\
\text { plated as } \\
\text { aggregate }\end{array}$} & \multirow{2}{*}{$\begin{array}{c}\text { No. of } \\
\text { hematopoietic } \\
\text { cells*/EB } \\
\text { and }(\%)\end{array}$} & \multicolumn{3}{|c|}{$\begin{array}{c}\text { Differential count of } \\
\text { hematopoietic cells/EB }\end{array}$} \\
\hline & & & & $\begin{array}{l}\text { Erythro- } \\
\text { blasts }\end{array}$ & $\begin{array}{l}\text { Macro- } \\
\text { phages }\end{array}$ & $\begin{array}{l}\text { Granulo- } \\
\text { cytes }\end{array}$ \\
\hline pig-a+ & $2.19 \pm 0.2$ & $2.41 \pm 0.1$ & $\begin{array}{c}1.18 \pm 0.1 \\
(49 \%)\end{array}$ & $48 \% \pm 4$ & $43 \% \pm 8$ & $9 \% \pm 7$ \\
\hline pig-a- & $1.02 \pm 0.1$ & $1.60 \pm 0.2$ & $\begin{array}{c}0.62 \pm 0.1 \\
(32 \%)\end{array}$ & $39 \% \pm 7$ & $59 \% \pm 7$ & $2 \% \pm 1$ \\
\hline
\end{tabular}

$* 10^{3}$; numbers represent the mean $\pm \mathrm{SD}$ of the cell number obtained from EBs in four (wild-type) or five (pig-a-) different experiments. yield. Hematopoietic colonies derived from pig- $a-$ ES cell EBs were mainly BFU-E and CFU-E, with very few CFU-GM (Table V).

\section{Discussion}

In this study we have investigated the hematopoietic differentiation of murine ES cells with an inactivating pig- $a$ mutation. Blood cells with the PNH phenotype were obtained both in living mice and directly from EBs. By each of these two approaches we have been able to circumvent early embryonic lethality of pig- $a$ - mice, and thus we have shown that pig- $a-\mathrm{ES}$ cells can differentiate into mature red cells, granulocytes, and lymphocytes. Comparison with the pattern of hematopoiesis in patients with PNH revealed interesting parallels in growth and differentiation, but it also demonstrated that an inactive pig- $a$ gene is not enough to cause PNH.

pig-a-ES cells contribute in vivo to erythro-myelo- and lymphopoiesis. In the blood of mice chimeric for a nonfunctional pig- $a$ gene, normal and PNH cells coexist, thus mimicking the two populations of blood cells we see in patients with PNH. As recently reported by Kawagoe et al. (30), we found red cells and lymphocytes deficient in GPI-anchored proteins in these mice. We observed contribution to erythropoiesis more commonly than to lymphopoiesis. In addition, we also found in one mouse granulocytes deficient in GPI-linked proteins. This implies that pig- $a-$ ES cells give rise to hematopoietic stem cells that are able to contribute to erythroid, myeloid, and lymphoid lineages. pig- $a-$ hematopoietic stem cells, however, tend to mature preferentially along the erythroid lineage and less easily along the myeloid and lymphoid lineages. The fact that lymphocytes are less frequently affected by the PNH abnormality is consonant to what we observe in patients with PNH. When lymphocytes are involved, both in mice and in humans both $\mathrm{B}$ and $\mathrm{T}$ cells are affected. This striking parallel suggests a similar mechanism controlling differentiation of pig- $a-$ (or PIG-A-) hematopoietic stem cells in our chimeras and in humans with the disease. The fact that granulocytes deficient in GPI anchors were only documented in one out of seven mice with pig- $a-$ red cells is in contrast to patients with $\mathrm{PNH}$, in whom we usually find a substantial proportion of granulocytes deficient in GPI-linked proteins. It is not clear if this discrepancy is due to an intrinsic difference in myelopoiesis in mice versus humans (which may be related to the low granulocyte count in mouse and particularly in the C57BL/6 strain) (31), or to circumstances that favor myelopoiesis in patients with $\mathrm{PNH}$, and that are absent in mice chimeric for a nonfunc- 


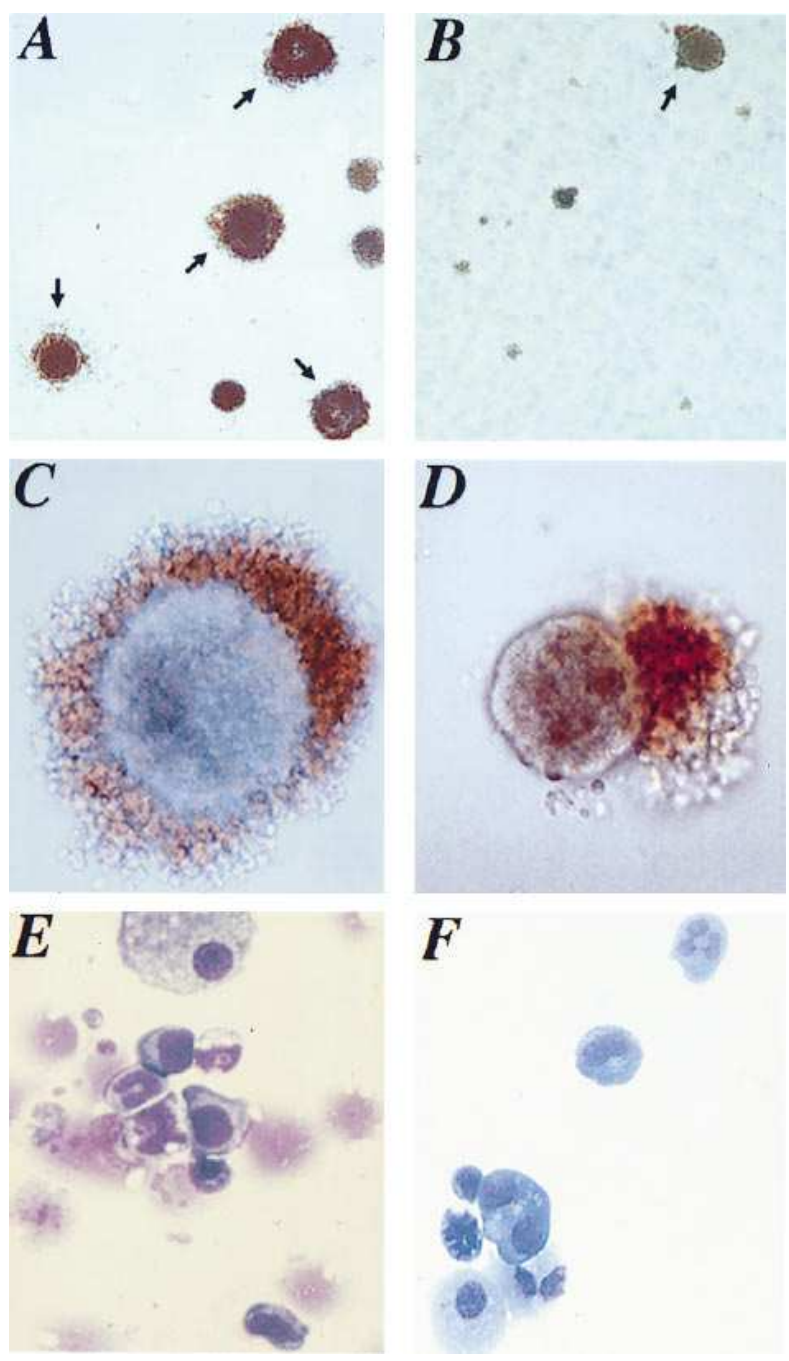

Figure 5. Hematopoietic differentiation in pig-a-EBs. EBs derived from wild-type $(A)$ and from pig-a- ES cells $(B)$ after $8 \mathrm{~d}$ in methylcellulose culture. The arrows show EBs with hematopoietic differentiation. Note smaller size of EBs in $B$ (original magnification $\times 100$ ). Hematopoietic differentiation in EBs derived from wild-type $(C)$ and from pig- $a-$ ES cells $(D)$ (original magnification $\times 600$ ). Cytospin preparation from wild-type $(E)$ and pig- $a-$ EBs $(F)$ with hematopoietic differentiation: erythroid and myeloid cells are present both in wild-type and in pig-a- EBs. Staining was with May Grünwald Giemsa or Wright, respectively (original magnification $\times 400$ ). tional pig-a protein. $10 \%$ of CFU-GM obtained from the liver of a fetus at 14 d.p.c. with $7 \%$ of pig- $a-$ red cells were rearranged in the pig- $a$ gene, confirming that pig- $a-$ hematopoietic progenitors can undergo myeloid differentiation. After birth, granulocytes with the PNH phenotype could only be documented at the age of $4 \mathrm{wk}$, but not later.

A characteristic of pig- $a-$ hematopoiesis in mice chimeras is a rapid decrease of CD24-deficient red cells after birth. This prompted us to look for pig- $a-$ red cells in the fetus. Indeed, we found that the percentage of red cells deficient in CD24 was much higher in the fetus; up to $36 \%$ was observed in a fetus of $17 \mathrm{~d}$ gestational age (see Fig. 4). We can suggest three not mutually exclusive explanations: (a) In analogy to what happens in patients with $\mathrm{PNH}$, a rapid decrease of red cells with the PNH phenotype could result from lysis due to complement activation after birth. We were not able to confirm this directly because the red cells with a PNH phenotype were too few to perform an acidified serum test (32) adapted to mice; in addition, it has not yet been proven that complement regulatory molecules on mouse red cells are GPI-linked. (b) The high proportion of PNH red cells in fetal life may signify a high contribution of pig- $a-$ cells also to the formation of other organs, and thus may cause increased perinatal lethality. In fact, the two fetuses with the highest proportion of red cells lacking GPI-linked proteins showed abnormalities of visceral organs that were probably incompatible with life. (c) pig- $a-$ hematopoietic stem cells may have a defect in their ability to home to the bone marrow. During mouse development, definitive hematopoiesis, which starts in the aorta-gonad-mesonephros region (33), shifts to the fetal liver around 12 d.p.c., and just before birth to the spleen and to the bone marrow (34). Thus, the pig- $a$ - red cells we detected in 11 fetuses and in 7 young mice may have been all products of hepatic hematopoiesis; by contrast, pig- $a-$ blood cells that must have definitely derived from bone marrow hematopoiesis were observed in only one mouse (2A8). In this respect, it has been reported that GPI-linked proteins play a role in adhesion to bone marrow fibroblasts (35).

In contrast to pig- $a$ - red cells and granulocytes, in the only mouse that had B and T lymphocytes deficient in GPI-linked proteins, their numbers were almost constant over an observation period of $12 \mathrm{mo}$. This finding is consonant with the persistence of lymphocytes deficient in GPI-linked proteins in patients with long-term spontaneous remission of PNH (36), and it suggests that in a normal environment as well as in patients who are in remission, the negative selection to which $\mathrm{PNH}$ red

\section{$\begin{array}{llllllll}1 & 2 & 3 & 4 & 5 & 6 & 7 & 8\end{array}$ $\stackrel{a}{a} \stackrel{a}{a} \stackrel{a}{a} \stackrel{a}{a} \stackrel{a}{a} \stackrel{a}{a} \stackrel{a}{a} \stackrel{a}{a} \stackrel{a}{a}$ V1 V2 WT M}

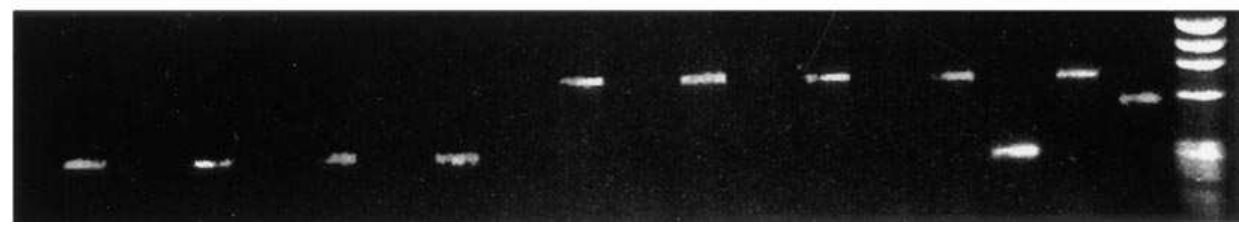

Figure 6. PCR analysis of pig- $a$ gene in pig- $a-$ EBs with hematopoietic differentiation. DNA from individual pig- $a$ - EBs showing hematopoietic differentiation was analyzed using two different primer sets only amplifying the wild-type pig- $a$ gene (a) and only amplifying the recombined pig-a gene (b) (see Methods). EBs 1-4 were derived from clone 97 (vector 1, V1) and EBs 5-8 were derived from clone $2 \mathrm{~A} 8$ (vector $2, \mathrm{~V} 2$ ). Only the recombined pig- $a$ genes were amplified. WT, wild-type EB; $\mathrm{M}$, molecular weight marker. 
Table V. Hematopoietic Progenitors Derived from Wild-type and pig-a-EBs

\begin{tabular}{lcrrr}
\hline & \multicolumn{4}{c}{ Colonies* $^{*}$} \\
\cline { 2 - 5 } & CFU-GEMM & \multicolumn{1}{c}{ BFU-E } & \multicolumn{1}{c}{ CFU-E } & CFU-GM \\
\hline Wild-type EBs & $9 \pm 6$ & $84 \pm 29$ & $146 \pm 70$ & $37 \pm 28$ \\
pig- $a$-EBs & 0 & $2 \pm 0.5$ & $4 \pm 2.9$ & $1 \pm 0.4$ \\
\hline
\end{tabular}

*No. of colonies \pm SD obtained by plating $10^{5}$ cells derived from day 6 EBs in four different experiments.

cells and granulocytes succumb does not similarly affect PNH lymphocytes. In fact, in chimeric mice obtained after injection of pig-a- ES cells into rag-1- blastocysts, lymphopoiesis is rescued and supported for a lifetime by $\mathrm{PNH}$ lymphocytes (V. Rosti, unpublished observation). Because finding GPI-negative lymphocytes in pig-a- chimeric mice is rare, it is important that we were able to confirm the finding by Kawagoe et al. (30), that the percentage of pig- $a$ - lymphocytes is about tenfold higher amongst $\mathrm{T}$ cells than amongst $\mathrm{B}$ cells. We can not tell whether this is because the pig- $a-$ status interferes with differentiation along the $\mathrm{B}$ cell pathway more than along the $\mathrm{T}$ cell pathway, because this status affects susceptibility to apoptosis differently in B cells and T cells, because GPI-negative B cells are less likely to be released in the peripheral blood, or any combination of the above.

pig-a-hematopoiesis in an environment devoid of GPIlinked proteins. The above findings indicate clearly that pig-ahematopoietic cells produce all mature blood cells, but we should consider that both in chimeric mice and in PNH patients the environment is pig- $a+$. To investigate pig- $a-$ hematopoiesis in an environment devoid of GPI-linked proteins, and also to circumvent embryonic death of pig- $a-$ mice, we studied hematopoiesis in pig- $a-$ EBs $(25,37)$. Upon withdrawal of leukemia inhibitory factor and of stromal contact, both pig- $a-$ and wild-type ES cells formed in methylcellulose EBs, consisting of globular aggregates of differentiated cell types that appear in a well-defined temporal pattern. Compared with wild-type ES-cells, pig-a- ES cells formed fewer EBs, and these were smaller in size and structurally abnormal (see Fig. 5), confirming that the GPI-linked proteins are important in early embryonic development. Although the morphology of pig-a- EBs was abnormal, hematopoietic differentiation did take place in them with full maturation into red cells, macrophages, and granulocytes (see Fig. 5). The number of pig-a- EBs with hematopoietic differentiation and the number of hematopoietic cells within an individual pig- $a-$ EB were lower when compared to wild-type EBs (see Table IV), demonstrating that in the absence of GPI-linked proteins, hematopoiesis occurs, but is severely impaired. Cells produced by pig- $a-$ EBs were mainly erythrocytes and macrophages; mature granulocytes were observed less frequently than in wild-type EBs (see Table IV). The low number of CFU-GM obtained in progenitor assays from pig- $a-$ EBs supports the notion that maturation into granulocytes is impaired. This might be related to the fact that GPI-linked proteins in stromal cells may positively influence granulocytic maturation (38-40).

Our finding that pig- $a-$ EBs undergo hematopoietic differentiation is in apparent contrast with the finding reported by Dunn et al. (41). It could be that the only clone they tested was defective like our clone 108 which had probably lost its totipo- tency since it failed not only to undergo hematopoietic differentiation in EBs (Table III), but also to produce chimeric mice (Table I). Perhaps a more attractive explanation of this discrepancy, however, relates to the use by Dunn et al. of a liquid culture system to form EBs. Indeed, recently Bielinska et al. (42) observed that in EBs derived from GATA4-/- ES cells, blood islands were formed only in methylcellulose, but not in liquid culture. GATA4-/- EBs are unable to form the visceral endoderm, suggesting that this structure is essential for organizing and retaining blood islands in suspension culture. Interestingly, pig- $a-\mathrm{EBs}$ formed in liquid culture resemble to some extent GATA4-/- EBs in that they also fail to form cystic cavities (our observation and [41]). Thus, pig- $a-$ EBs, being unable to form visceral endoderm, may simply lose their hematopoietic cells into the medium. This would also explain why hematopoietic differentiation is restored in pig-a-/pig-a+ chimeric EBs in which visceral endoderm can be contributed by the normal ES cells (41).

Our own results on pig- $a-$ EBs formed in methylcellulose, however, suggest a real impairment of hematopoiesis. Since this was observed in two independent clones, it is not likely to be an artifact; rather, it is likely to be a direct effect of the lack of GPI-linked proteins. As a further control, we found hematopoietic differentiation similar to wild-type in EBs obtained from three nonhomologously recombined ES cell clones.

The proportion of pig- $a-$ EBs showing hematopoietic differentiation increased when, instead of plating single cell suspensions, we plated small cell aggregates in the methylcellulose assay, suggesting that cell-to-cell contact may partially compensate for the lack of GPI-linked proteins. Since this procedure also facilitated the formation of pig- $a-$ EBs themselves, it could be that the restored hematopoietic differentiation is a consequence of this.

A mutation in the pig-a gene is not sufficient to cause PNH. Our results demonstrate that pig- $a$ - hematopoietic differentiation can occur both in vivo, in an environment that is chimeric for a nonfunctional pig- $a$ gene, and in vitro, in an environment that completely lacks GPI-linked proteins. In both cases, however, hematopoiesis is quantitatively impaired. Our clinical case of a mouse that developed pancytopenia and an increased proportion of $\mathrm{PNH}$ red cells has a striking analogy to patients with aplastic anemia developing $\mathrm{PNH}$; it provokes speculations on a common cause impairing normal hematopoiesis, but sparing the PNH cells. The deficiency of one or more GPI-linked proteins is responsible for the survival advantage of the $\mathrm{PNH}$ cells; however, the precise mechanism through which stem cells with the PNH phenotype are spared remains unclear (16). Taken together, our results strongly support our initial hypothesis that pig- $a$ inactivation per se does not provide the hematopoietic stem cell with a proliferative advantage, and that therefore in patients with $\mathrm{PNH}$, some additional factor(s) must be leading to the expansion of the mutant clone. pig- $a-$ hematopoiesis in mice and EBs might serve as a tool to define these additional factor(s), which will be crucial for the understanding of the pathogenesis of $\mathrm{PNH}$ and its relation to aplastic anemia.

\section{Acknowledgments}

We thank Tom Gridley for providing CJ7 ES cell line, Michel Sadelain for providing the BamHI-NcoI fragment of the IRES from en- 
cephalomyocarditis virus, and Andreas Kottmann for providing the NcoI-BglII fragment of pnLacF-puc18. We also thank Nicola Hawe for the help with the culture of ES cells, and Rosario Notaro for critical reading of the manuscript.

V. Rosti was supported by the Ferrata Storti Foundation. This work was supported by a grant from the National Institutes of Health (grant no. RO1-HL-56678-01).

\section{References}

1. Dacie, J.V., and S.M. Lewis. 1972. Paroxysmal nocturnal haemoglobinuria: clinical manifestations, haematology and nature of disease. Ser. Haematol. 3:3-23.

2. Takeda, J., T. Miyata, K. Kawagoe, Y. Iida, Y. Endo, T. Fujita, M. Takahahi, T. Kitani, and T. Kinoshita. 1993. Deficiency of the GPI anchor caused by a somatic mutation of the PIG-A gene in paroxysmal nocturnal hemoglobinuria. Cell. 73:703-711.

3. Bessler, M., P.J. Mason, P. Hillmen, T. Miyata, N. Yamada, J. Takeda, L. Luzzatto, and T. Kinoshita. 1994. Paroxysmal nocturnal haemoglobinuria (PNH) is caused by somatic mutations in the PIG-A gene. EMBO (Eur. Mol. Biol. Organ.) J. 13:110-117.

4. Rosse, W.F. 1990. Phosphatidylinositol-linked proteins and paroxysmal nocturnal hemoglobinuria. Blood. 75:1595-1601.

5. Kinoshita, T., N. Inoue, and J. Takeda. 1995. Defective glycosyl phosphatidylinositol (GPI)-anchor synthesis and paroxysmal nocturnal hemoglobinuria. Adv. Immunol. 60:57-103.

6. Masterson, W., T. Doering, G. Hart, and P.T. Englund. 1989. A novel pathway for the glycan assembly: biosynthesis of the glycosyl-phosphatidylinositol anchor of the trypanosome variant surface glycoprotein. Cell. 56:793-800.

7. Bessler, M., P. Hillmen, L. Longo, L. Luzzatto, and P.J. Mason. 1994. Genomic organisation of the X-linked gene (PIG-A) that is mutated in paroxysmal nocturnal haemoglobinuria and of a related pseudogene mapped to $12 \mathrm{q} 21$. Hum. Mol. Genet. 3:751-757.

8. Watanabe, R., T. Kinoshita, R. Masaki, A. Yamamoto, J. Takeda, and N. Inoue. 1996. PIG-A and PIG-H, which participate in glycosylphosphatidylinositol anchor biosynthesis, form a protein complex in the endoplasmic reticulum. J. Biol. Chem. 271(43):26868-26875.

9. Luzzatto, L., and M. Bessler. 1996. The dual pathogenesis of paroxysmal nocturnal hemoglobinuria. Curr. Op. Hematol. 3:101-110.

10. Rosse, W., and R.E. Ware. 1995. The molecular basis of paroxysmal nocturnal hemoglobinuria. Blood. 86:3277-3286.

11. Rosse, W.F., and J.V. Dacie. 1966. Immune lysis of normal human and paroxysmal nocturnal haemoglobinuria $(\mathrm{PNH})$ red blood cells. I. The sensitivity of PNH red cells to lysis by complement and specific antibody. J. Clin. Invest. 45:736-748.

12. van Kamp, H., J.E. Landegent, R.P.M. Jansen, R. Willemze, and W.E. Fibbe. 1991. Clonal haematopoiesis in patient with acquired aplastic anaemia. Blood. 78:3209-3214.

13. Dameshek, W. 1967. Riddle: what do aplastic anaemia, paroxysmal nocturnal haemoglobinuria (PNH) and hypoplastic anaemia have in common? Blood. 30:251-254.

14. Lewis, S.M., and J.V. Dacie. 1967. The aplastic anaemia-paroxysmal nocturnal haemoglobinuria syndrome. Br. J. Haematol. 13:236-251.

15. Rotoli, B., and L. Luzzatto. 1989. Paroxysmal nocturnal haemoglobinuria. Baillière's Clin. Haematol. 2:113-138.

16. Luzzatto, L., M. Bessler, and B. Rotoli. 1997. Somatic mutation in Paroxysmal Nocturnal Hemoglobinuria: a blessing in disguise? Cell. 88:1-4.

17. Bessler, M., P.J. Mason, P. Hillmen, and L. Luzzatto. 1994. Somatic mutations and cellular selection in paroxysmal nocturnal haemoglobinuria. Lancet. 343:951-953

18. Swiatek, P.J., and T. Gridley. 1993. Peinathal lethality and defects in hindbrain development in mice homozygous for a targeted mutation of the zinc finger gene Krox20. Genes Dev. 7:2071-2084.

19. Robertson, E.J. 1987. Embryo-derived stem cell lines. In Teratocarcinomas and embryonic stem cells: A practical approach. E.J. Robertson, editor. IRL Press, Oxford, UK. 71-112.

20. Sambrook, J., E.F. Fritsch, and T. Maniatis. 1989. Molecular cloning: a laboratory manual. Cold Spring Harbor Laboratory Press.

21. Kawagoe, K., J. Takeda, Y. Endo, and T. Kinoshita. 1994. Molecular cloning of murine Pig-a, a gene for GPI-anchor biosynthesis, and demonstration of interspecies conservation of its structure, function, and genetic locus. Genomics. 23:566-574.

22. Laird, P., A. Zijderveld, K. Linders, M. Rudnicki, R. Jaenisch, and A. Berns. 1991. Simplified mammalian DNA isolation procedure. Nucleic Acids Res. 19:4293.

23. Longo, L., A. Bygrave, F.G. Grosveld, and P.P. Pandolfi. 1997. The chromosome make-up of mouse embryonic stem cells is predictive of somatic and germ line chimerism. Transgenic Res. 6:1-8.

24. Pevny, L., C.-S. Lin, V. D'Agati, M.C. Simon, S.H. Orkin, and F. Constantini. 1995. Development of hematopoietic cells lacking transcription factor GATA-1. Development (Cambridge). 121:163-172.

25. Wiles, M.V., and G. Keller. 1991. Multiple hematopoietic lineages develop from embryonic stem (ES) cells in culture. Development (Cambridge). 111:259-267.

26. Heyworth, C., and E. Spooncer. 1993. In vitro clonal assays for murine multipotential and lineage restricted myeloid progenitor cells. In Haemopoiesis: A Practical Approach. N. Testa, and G. Molineux, editors. Oxford University Press, Inc., New York. 37-53.

27. Stowe, H., J. Wagner, and J. Pick. 1971. A debilitating fatal murine dermatitis. Lab Anim. Sci. 21:892-897.

28. HogenHesch, H., M.J.J. Gijbels, E. Offerman, J.v. Hooft, D.W.v. Bekkum, and C. Zurcher. 1993. A spontaneous mutation characterized by chronic proliferative dermatitisin C57BL mice. Am. J. Pathol. 143:972-982.

29. Wiles, M.V. 1993. Embryonic stem cell differentiation in vitro. In Guide to Techniques in Mouse Development, Volume 225. P.M. Wassarman and M.L. DePamphilis, editors. Academic Press, Inc. 901-918.

30. Kawagoe, K., D. Kitamura, M. Okabe, I. Taniuchi, M. Ikawa, T. Watanabe, T. Kinoshita, and J. Takeda. 1996. Glycosylphosphatidylinositol-anchordeficient mice: implications for clonal dominance of mutant cells in paroxysmal nocturnal hemoglobinuria. Blood. 87:3600-3606.

31. Russell, E.S., and S.E. Bernstein. 1966. Blood and blood formation. In Biology of the Laboratory Mouse. E.L. Green, editor. McGraw-Hill Inc., New York. 351-372.

32. Ham, T.H. 1937. Chronic haemolytic anaemia with paroxysmal nocturnal haemoglobinuria: study of the mechanism of haemolysis in relation to acidbase equilibrium. N. Engl. J. Med. 218:915-918.

33. Medvinsky, A., and E. Dzierzak. 1996. Definitive hematopoiesis is autonomously initiated by the AGM region. Cell. 86:897-906.

34. Moore, M.A.S., and D. Metcalf. 1970. Ontogeny of the hematopoietic system: yolk sack origin of in vivo and in vitro colony forming cells in the developing mouse embryo. Br. J. Haematol. 18:279-296.

35. Gordon, M., J. Lewis, S. Marley, F. Grand, and J. Goldman. 1997. Stromal cells negatively regulate primitive hemopoietic progenitor cell activation via a phosphatidylinositol-anchored cell adhesion/signalling mechanism. $B r . J$. Haematol. 96:647-653.

36. Hillmen, P., M.S. Lewis, M. Bessler, L. Luzzatto, and J.V. Dacie. 1995. Natural history of paroxysmal nocturnal hemoglobinuria. N. Engl. J. Med. 333 : $1253-1258$.

37. Doetschman, T., H. Eistetter, M. Katz, W. Schmidt, and R. Kemler. 1985. The in vitro development of blastocyst-derived embryonic stem cell lines: formation of visceral yolk sac blood island and myocardium. J. Embryol. Exp. Morph. 87:27-45.

38. Gordon, M.Y., G.P. Riley, S.M. Watt, and M.F. Greaves. 1987. Compartmentalization of a haematopoitic growth factor (GM-CSF) by glycosaminoglycans in the bone marrow microenvironment. Nature (Lond.). 326:403-405.

39. Roberts, R., J. Gallagher, E. Spooncer, T. Allen, F. Bloomfield, and T. Dexter. 1988. Heparan sulphate bound growth factors: a mechanism for stromal cell mediated haemopoiesis. Nature (Lond.). 332:376-378.

40. Brunner, G., G. Janice, D.B. Rifkin, and E.L. Wilson. 1991. Phospholipase $\mathrm{C}$ release of basic fibroblast growth factor from human bone marrow cultures as a biologically active complex with a phosphatidylinositol-anchored heparan sulphate proteoglycan. J. Cell Biol. 114:1275-1283.

41. Dunn, D.E., J. Yu, S. Nagarajan, M. Devetten, F.F. Weichold, M.E. Medof, N.S. Young, and J.M. Liu. 1996. A knock out model of paroxysmal nocturnal hemoglobinuria: Pig-a-hematopoiesis is reconstituted following intercellular transfer of GPI-anchored proteins. Proc. Natl. Acad. Sci. USA. 93:79387943.

42. Bielinska, M., N. Narita, M. Heikinheimo, S.B. Porter, and D.B. Wilson. 1996. Erythropoiesis and vasculogenesis in embryoid bodies lacking visceral yolk sac endoderm. Blood. 88:3720-3730. 